\title{
ESPAÑOL SER / ESTAR, UNA CLAVE O MÚLTIPLES CLAVES. REVISIÓN DE UNA BÚSQUEDA INTERMINABLE
}

\begin{abstract}
Resumen. Desde hace cuatro siglos, los verbos españoles ser y estar han sido explicados de manera reduccionista como la oposición de nociones dicotómicas del tipo duración / transitoriedad, inherencia / accidente, permanencia / transitoriedad, cambio / no cambio, etc. Tales teorías binarias suponen una visión logicista del lenguaje y constituyen un error que ha lastrado tanto la comprensión del complejo fenómeno de ser y estar en español como su explicación didáctica. Los usos de estos dos verbos solamente se pueden entender desde el reconocimiento de su polisemia y polifuncionalidad y de la existencia de múltiples y diferentes patrones que subyacen a la formación de enunciados con ser y con estar.
\end{abstract}

Palabras clave: gramática española, verbos copulativos: ser y estar, logicismo en el análisis lingüístico, polisemia, gramaticalización.

\section{Introducción}

Uno de los grandes errores en el estudio del uso de los verbos ser y estar es negar la polisemia de estas formas. Este error parte de la presunción de que el hablante, al producir sus enunciados con ser y estar, parte de grandes principios unitarios y cohesionados y no de múltiples patrones de formación de enunciados basados en decenas de valores que tienen estos verbos como los relativos a la salud, aspecto físico, degustación, etc. Esos principios, supuestamente capaces de explicar todos los usos y apariciones de ser / estar, se plantean como oposiciones binarias tales como duración / transitoriedad, inherencia / accidente, permanencia / transitoriedad, cambio / no cambio, etc. Se parte, por tanto, no solo de

\footnotetext{
* Universidad de Granada.
}

* Universidad de Córdoba. 
ignorar la polisemia de estos verbos ${ }^{1}$ sino también de la idea equivocada de que si existe una forma gramatical debe de existir una palabra, una lexicalización, capaz de abarcar los valores de dicha forma gramatical. En cierta medida, las discusiones sobre ser / estar se parecen, a veces, a la búsqueda de una palabra mágica capaz de resolver, de una vez por todas, el problema. La realidad, sin embargo, es que ser y estar son elementos polisémicos y polifuncionales difíciles de explicar y de enseñar, precisamente por su polivalencia y por los contrastes y oposiciones que son capaces de establecer en determinados contextos. Se trata pues de un problema complejo que afecta a miles de adjetivos y participios (y nombres) que participan en docenas de diferentes paradigmas de formación de enunciados. Vañó-Cerdá (1982: 2) resume así el problema de ser / estar, apuntando algunas de las claves de la complejidad del mismo:

¿Por qué es tan complejo este problema de los usos de ser y estar con adjetivos en el español actual? La razón de dicha complejidad no es otra que esta: miles y miles de adjetivos ricos en contenido semántico, esto es con múltiples significados empleados en muy diversos contextos por millones y millones de hispanohablantes (procedentes de diversas regiones, lenguas y dialectos, como Castilla, Cataluña, Galicia, Andalucía, León, Aragón, etc., e Hispanoamérica) durante siglos y siglos (a través de los cuales la lengua ha ido no solo evolucionando, sino también anquilosándose y dejando residuos en la corriente de su evolución), han venido agrupándose en estructuras semántico- sintácticas en torno a ser y estar dirigidos no únicamente por las leyes de la lógica y de una manera consecuente, sino también por los más diversos motivos, como pueden ser la analogía, la estilística, la costumbre, la pragmática, e, incluso, la libertad y licencias que puede tomarse cualquier hablante en contra de las normas de la lengua común.

\section{Ser y estar como problema gramatical de la lengua española}

Los verbos ser y estar constituyen un importante punto de interés dentro de los estudios de la lengua española. Este interés nos fuerza a preguntarnos cuestiones tales como: ¿Qué es lo que hace que los verbos ser y estar sean un problema de tanto relieve? ¿Por qué después de tantos

${ }^{1}$ Son pocos y tímidos los autores que difieren de estas soluciones dicotómicas. Así, Roldán (1970: 74) señala que en las diversas construcciones con ser o estar, los gramáticos no han sido capaces de detectar las extensiones naturales de los significados básicos de los dos verbos. 
años de insistencia sobre el tema, este sigue provocando apasionadas discusiones en libros y revistas profesionales?

Sobre la excepcional posición que ocupa ser-estar dentro del sistema gramatical del español y las dificultades que presenta para el estudiante extranjero, el acuerdo de los expertos es prácticamente general. Los problemas de ser y estar se perciben, quizá más fácilmente, desde la óptica de una lengua extranjera, $y$, por consiguiente, es desde la perspectiva de los profesores que han de explicar de alguna manera a sus alumnos cómo han de usar uno y otro verbo, donde han surgido muchas de las más notables e importantes aportaciones sobre el tema. Respecto a la diferencia con las otras lenguas, se trata, según dice Bull (1965: 291), «del paso de una categoría coalescente a una bifurcada». Esto es patente si comparamos el sistema copulativo español con el sistema copulativo de algunas de las lenguas más afines a nuestro idioma, donde verbos tales como to be, être, essere, etc., tienen que ser traducidos al español por medio de los dos verbos, ser y estar, según aparezca en unos contextos o en otros. Está claro que para un francés, un inglés, un italiano, etc., se plantea un problema, ya que tiene que hacer una elección en unas circunstancias poco definidas, mientras que al español que trata de hablar en estas otras lenguas, no se le plantea tal problema, pues a él se le presenta la fusión de dos verbos de su lengua materna en uno solo de la lengua extranjera, lo cual no le obliga, ni a forzar su inteligencia ni a echar mano de una preparación lingüística especial en ese idioma.

Para Bolinger, «la oposición ser / estar, conceptualmente la oposición entre esencia y accidente, es para los estudiantes de español de habla inglesa el rasgo más notorio de este idioma». G. Cirot vio ya el problema de ser / estar como «un pequeño misterio»; otros, como Américo Castro y Julián Marías lo han catalogado como una cuestión de «forma interior del lenguaje», de la que se deduciría, entre otras cosas, una pretendida preocupación histórica del español por lo concreto. Pérez de Ayala lleva al límite estas opiniones, considerando al español como un filósofo innato, ya que sabe distinguir espontáneamente entre la esencia y la existencia transitoria por medio del uso de ser o de estar.

Desde el Renacimiento al siglo XIX, todas las gramáticas de la lengua española han tratado sobre el uso de los verbos ser y estar. La explicación que durante muchos años se ha dado de ser y estar podría ejemplificarse con el siguiente texto tomado de la gramática del español para extranjeros de Caesare Ovdino, fechada en el siglo XVII: «Diferimen significationis verborum ser o estar, in eo positium est, quod ser denotet essentiam rei in qualitate vel quantitate: ut. ser bueno, ser malo, ser grande, pequeño coxo 
\& c. Estar vero existere in aliquo loco: vt. yo estoy en Roma, sum Romae; yo he estado en París; fui Lutetia».

Más adelante, en esta misma gramática, se hace mención a que los españoles cuando quieren preguntar por la salud de alguien usan estar, diciendo: ¿Cómo está v. m.? qui vales, respondiéndose también con estar: 'No estoy muy bueno', 'Non admodum valeo'. Se señala que en estos casos bueno y malo no significa bonum et malum, adjetivos, sino de una manera adverbial, bene et male. Se resumen finalmente los usos de estar diciendo que se usa este verbo en todas las cosas que denotan pasión o afecto del alma: ayrado esta, iratus est, vel, ira excanduit.

Por otra parte, dice Ovdino, se observa que, de los cuatro verbos auxiliares de la conjugación, hauer, tener, ser et estar, el primero es el auxiliar de la acción y el tercero (ser) de la pasión.

Esta es la opinión general que fue recogida posteriormente por la Academia y atacada por Bello (1970 [1847]: 349) cuando indica que «Estar significa, no tanto, pasión; esto es, la impresión real o figurada que el agente hace en el objeto, cuanto el estado que es la consecuencia de ella», de donde proviene que si en La casa era edificada, la época de la acción es la misma del verbo auxiliar, en La casa estaba edificada; la época de la acción es anterior a la época del auxiliar.

Para Bello ser se aplica a las cualidades esenciales y permanentes, mientras que estar se aplica a las accidentales o transitorias. Refiriéndose al significado de ser, opina que «Es notable en el verbo ser la significación de la existencia absoluta, que propiamente pertenece al Ser Supremo: 'Yo soy el que soy'; pero que se extiende a los otros seres para significar el sólo hecho de la existencia».

La teoría de Bello de la oposición permanente-transitoria se establece como la explicación mas generalizada sobre ser / estar hasta que empieza a ser atacada por autores como Cirot, Hanssen y Andrade ${ }^{2}$. Hanssen propone su dicotomía perfectivo-imperfectivo para resolver el problema. Según Hanssen, «las frases con estar son perfectivas y las frases con ser imperfectivas: mi hermano está enfermo; todavía está joven; ya está viejo; mi tío es

${ }^{2}$ Un ejemplo de crítica a la dicotomía permanente-transitorio nos lo ofrece Justo Fernández López cuando afirma que «el verbo estar tiene un carácter mucho más enfático y emocional que el verbo ser, por ser un verbo más subjetivo. No quiere decir que el verbo estar exprese estados transitorios. Los estados que compara o contrasta pueden ser permanentes e incluso inherentes y normales. Pero lo hace con más énfasis que el verbo ser. [...] Vamos a El Mesón del Labrador, allí el cocido está excelente. No quiere decir que el cocido en ese local unas veces es bueno y otras malo. No, el hablante usa en este caso estar para denotar que ha comido en otros locales, pero el cocido de El Mesón del Labrador es de lo mejor». 
vigoroso». Esta explicación de Hanssen pasó prácticamente desapercibida hasta ser defendida, años más tarde, por Samuel Gili Gaya.

Otra dicotomía utilizada para el estudio de ser y estar es la de estadoacción. Bello, como se ha indicado, asocia estar con la idea de estado. Posteriormente, Hanssen $(1913: 179,247)$ asigna a ser la expresión del acto y a estar la atribución del estado, pero articulando esta dicotomía con la de acción perfectiva-imperfectiva.

Para Cirot (1930: 107 y sig.) estar con participio, indica un estado resultante de un acto anterior, mientras que ser con participio, indica un estado pasivo. Con adjetivos, estar indica un estado nuevo o accidental, mientras que ser expresa una relación entre el sujeto y el predicado.

Tanto Bello como Hanssen y otros autores como Salvá, Lenz, y, posteriormente, Roca Pons, Amado Alonso y Henríquez Ureña, etc., desarrollaron estas dicotomías, junto con los usos característicos y propios de ser y de estar, para intentar una explicación global de las apariciones de ser / estar tanto con adjetivos como con participio. Dentro de estas explicaciones merece destacarse la aproximación al problema propuesta por J. Andrade en 1919, siempre en un intento de terminar con la explicación de la oposición permanente-transitorio para ser / estar. Para Andrade, la clave está en que con estar se expresa una experiencia o perfección inmediata: jestá buena la sopa!, mientras que ser se usa para la expresión de una idea general, que sabemos o que creemos, y que, por tanto, no necesitan de una comprobación inmediata: La nube es blanca. Según esto, indica Andrade, estar sirve de nexo a las atribuciones afectivas, mientras que ser establece relaciones lógicas. Estas ideas, valiosísimas en cuanto suponen la entrada del factor subjetivo en la elección de ser / estar, fueron posteriormente desarrolladas y matizadas por Bull y Bolinger.

En 1925, S. Griswold Morley publicó su obra «Modern Uses of Ser and Estar». Trabajo este que trata de ser una recapitulación de las opiniones existentes sobre el tema y un análisis de los ejemplos de uso de ser y estar que no encajan en las diversas teorías.

Para Morley no se puede reducir el problema de ser / estar a una sola ley y se propone, en consecuencia, explicar la distinción entre ser y estar según las siguientes cuatro dicotomías debidas a otros autores:

\begin{tabular}{|l|l|}
\hline \multicolumn{1}{|c|}{ Ser } & \multicolumn{1}{c|}{ Estar } \\
\hline I. Duración, inherencia. & I. Transitoriedad, accidentalidad. \\
II. Mera existencia. & II. Situación definida en el espacio. \\
III. Con participios pasados, acto. & III. Estado, con participios pasados \\
IV. Conceptos mentales. & o adjetivos. \\
& IV. Percepciones sensoriales. \\
\hline
\end{tabular}


Morley comprueba cada uno de estos principios con determinados usos de ser y estar que se ajustan en unos casos a ellos, y, en otros, parecen contradecirlo. El uso de ser para atribuir cualidades durativas o inherentes se ve confirmado en unos casos y en otros no, Así, dice Morley, el principio de inherencia falla también pues no es aplicable a una serie de adjetivos que expresan condiciones transitorias y que, sin embargo, se construyen habitualmente con ser. Tales son: joven, rico, viejo, pobre, feliz, infeliz, dichoso, desdichado (pero no alegre y contento). También incluye junto a estos a soltero, casado y viudo.

Dentro del segundo principio analizado por Morley se incluye el análisis del uso de ser para expresar la pura existencia y de estar para expresar la existencia, en cuanto viene matizada o asociada con circunstancias locales, sea en el sentido literal o figurado; así explica el ejemplo: los pocos sabios que en el mundo han sido (arcaísmo), frente a está en Madrid. Dice Morley, «Pero si el sujeto es material y el sentido de posición es literal, se usa ser». Da como ejemplos, la escena es en Madrid; allí es el piar triste; averiguad donde el duelo debe ser. Encontraremos después en Bull una clara explicación para estos casos de conflictividad que no se basan en la oposición tiempo-espacio, sino en la de entidad-proceso.

Morley sigue a Hanssen en el tercer principio, que asigna a ser la expresión del acto y a estar la atribución del estado. Los adjetivos que significan estado se construyen, casi siempre, con estar, aún cuando este estado sea duradero o permanente. Así, son conformes despierto, harto, junto, contento, lleno, solo y sus opuestos cuando existen.

Sobre el cuarto principio, basado en Andrade, según el cual ser atribuye conceptos y estar percepciones, o, lo que es lo mismo, la afectividad estaría expresada por estar y las relaciones lógicas, más frías, con ser, dice Morley que la connotación afectiva de estar es una característica secundaria y rechaza este principio. Morley, finalmente, se inclina por una solución de compromiso que incluye a todas estas dicotomías mencionadas, y concluye su trabajo con las siguientes afirmaciones:

a) No basta un solo principio para explicar todos los usos de ser y estar.

b) Prevalecen, sin embargo, las oposiciones durativo-transitorias y acto-estado. Las excepciones son numerosas.

c) Estar posee, además, su propio y original sentido locativo.

d) Lo conceptual o lo perceptivo entran, sin duda, como connotaciones secundarias.

e) Algunos ejemplos son puramente idiomáticos y sin posible explicación racional. El lenguaje es sentimiento y no razón. 
f) La posesión de estos dos verbos dota al español de una superior delicadeza y variedad de expresión. La práctica y el estudio permitirán al estudiante extranjero percibir los matices.

g) La distinción entre ser y estar es un rasgo más del afán de independencia y del individualismo del pueblo español.

La obra de Morley ha servido como base de discusión y especulación a numerosos lingüistas que, o bien han insistido en alguna de las cuatro dicotomías estudiadas por Morley, o bien han seguido un criterio ecléctico tratando de compaginar lo que en su opinión hay de válido en cada una de estas teorías.

Sin embargo, la ambición de encontrar una solución binaria, simple y contundente al problema de ser / estar, produciría mucha controversia en las décadas siguientes. Es el caso de William E. Bull, autor norteamericano defensor de una nueva dicotomía para ser / estar. Según Bull (1965: 293), el español organiza la realidad en dos criterios: cambio frente a no cambio. Y, de acuerdo con esto, todas las entidades están divididas en dos conjuntos: el de los que han sufrido algún cambio y el de los que no lo han sufrido. Según este autor, esta clasificación solo la puede hacer el hablante en el momento de la observación y la consecuente codificación del mensaje. Una persona enfrentada a una nueva entidad tiene que decidir si la entidad en cuestión ha sufrido o no previamente algún cambio. Dice Bull que «cuando la lógica y la existencia previa de entidades similares nos indica que algún cambio ha tenido lugar, la entidad se describe con estar. Así, el patrón de un restaurante que espera que los vasos estén limpios como resultado de una operación puede decir al camarero: este vaso está sucio. Por la misma lógica, los neumáticos de un automóvil están normalmente hinchados con aire y un conductor dirá, en caso de que no sea así: la llanta esta desinflada. Por el contrario, cuando el hablante no puede descubrir, ni por lógica ni por observación, que haya habido un cambio usara ser: 'Mira ese señor tan elegante, debe ser muy rico'».

De esto se deduce que ser será usado para describir todas las entidades que en la experiencia del hablante tienen características inmutables (las ovejas son mansas; el acero es muy fuerte; el hielo es frío; el agua de los océanos es salada). Aquellas entidades cuyas características no son inmutables pueden ser descritas por ser o por estar; en el caso de usarse ser se sugiere simplemente que, en opinión del hablante, dicha característica es normalmente estable.

Cuando una entidad cambia, el hablante debe ajustarse al cambio, $\mathrm{y}$, finalmente establecer una nueva norma para la entidad; es decir, poner estar en lugar de ser. Así, cuando un amigo gana peso de repente está gordo; cuando el hablante se acostumbra al cambio entonces el amigo es 
gordo. Sin embargo, siempre que se mencione el cambio se usará estar (Hasta tener veinte años era muy delgado. Hoy está gordo).

Asimismo, estar se usa para indicar que lo observado no se conforma con la idea previa que el hablante tenía. Así, dice Bull, una persona que no espera que unas montañas sean tan altas como son en realidad puede decir: ¡Qué altas están las montañas! Y, de la misma manera, aunque los metalúrgicos sepan que el acero es fuerte, un no especialista puede descubrirlo y utilizar estar: ¡Qué fuerte está el acero!

Diversos autores siguen a Bull, destacando entre ellos Dwight Bolinger y Ricardo Navas Ruiz. Bolinger (1944: 333-338) realiza numerosas aportaciones al problema de ser / estar, tomando como base las ideas de Bull, aclarándolas por una parte y matizándolas por otra. Basa su argumentación en la importancia que se ha de dar al hecho de que el lenguaje, al ser una herramienta usada por el hablante con unos fines y para conseguir unos objetivos, refleja en su funcionamiento no unos criterios objetivos rígidos sobre la naturaleza de la 'cosa', sino lo que el hablante desea que esa 'cosa' aparezca ante los demás. Por esto se debe rechazar la objetividad como criterio valido para ser / estar. De aquí que si podemos escoger entre Juan está calvo y Juan es calvo, o entre La madre es ciega y La madre está ciega, la elección se efectuará de acuerdo con un factor, que no es ni la esencia ni el accidente, sino el concepto subjetivo del hablante.

Para Navas Ruiz (1963) «cuantas teorías han nacido en derredor de ser y estar no son, en suma, sino enunciados de tipo estilístico. Y su error fundamental fue ofrecer como objetivo lo que no es sino subjetivo, presentar como universal lo que sólo parcialmente era válido». Para Navas, el hablante prescinde de considerar si los fenómenos son permanentes o transitorios, inherentes o accidentales, cualidades o estados, distinguiendo con más simplicidad lo que ve mudable y lo que no ve mudable. Este autor resume su formulación de la siguiente manera, «ser es el verbo de lo definitorio, de lo intemporal, de lo concebido subjetivamente al margen de la mutabilidad, de la mera relación atributiva. Estar es el verbo de la situación temporal, de la permanencia indefinida, de lo subjetivamente mutable». Las opiniones de Navas, por tanto, pueden insertarse perfectamente en la solución norma-cambio propuesta por Bull. 


\section{Conclusiones}

Después de haber repasado someramente algunas de las más importantes aportaciones al estudio de ser / estar, cabe preguntarse en qué medida está resuelto el problema. Como hemos podido comprobar al exponer brevemente algunas de las diversas teorías, algunos autores creen haber dado ya con la clave del problema, pensando que con ella han refutado las anteriores teorías y que han explicado completamente el fenómeno. Es evidente, sin embargo, que no se ha llegado a un consenso general sobre el tema y que la opinión mayoritaria queda expuesta por Félix Monge (1959: 227) cuando afirma que «hoy podemos concluir con las mismas palabras de Cirot (1930) el misterio está cercado, sitiado, pero no se ha rendido plenamente a nuestros ojos». Igual opinión aparece en los comentarios de estudios más modernos sobre ser / estar. Así, Johan Falk (1987) dice, a propósito de la obra de Vañó-Cerdá titulada Ser y Estar + Adjetivos, que «el libro es un digno sucesor de Navas Ruiz, al que supera, y válido por su concienzudo empirismo, pero no logra esclarecer del todo el 'pequeño misterio' de que habló Cirot hace más de cincuenta años».

Finalmente, al plantearse el tema de ser / estar desde el enfoque concreto de la enseñanza del español a extranjeros, Monje expone una teoría pesimista respecto a las posibilidades de poder explicar y predecir satisfactoriamente las apariciones de estos verbos:

Si el empleo de ser o estar responde a modos diversos de concebir por parte del individuo o de la colectividad (habla o lengua), es decir, a una innere Sprachform peculiar, es difícil, por no decir imposible, dar normas sobre los distintos usos. Puede llegarse a acotar usos indubitables y hasta a inventariarlos. Pero siempre quedará una amplia zona en donde el extranjero no podrá moverse con seguridad sin haber asimilado previamente nuestra forma lingüística interior. Precisamente la zona cuyo conocimiento exigirá el del habla en cualquiera de sus actualizaciones, la total posesión de nuestras actitudes mentales, la íntima comprensión del sistema.

Esta opinión de Monje curiosamente es compartida por muchos tratadistas y estudiosos con la rotunda afirmación de que ser / estar nunca se podrá explicar por entero. En realidad no es cierto, sí que se puede y se podrá dar cuenta por entero del problema, siempre que se esté dispuesto a reconocer la complejidad del mismo, y a aceptar, en su descripción y representación, los índices de vacilación, variación e imprecisión que la extensión histórica, geográfica y sociolingüística imponen. 


\section{Bibliografía}

ANDRADE, M. (1919). «This distinction between Ser and Estar», Hispania, II, 19-23.

BELLO, A. (1970 [1847]). Gramática de la Lengua Castellana. Buenos Aires: Ed. Sopena, Argentina.

BOLINGER, D. (1944). «More on Ser and Estar», Modern Language Journal of New York, XXVIII, 3, 333-338.

BOLINGER, D. (1947). «Still more on 'ser' and 'estar'», Hispania, XXX, 361-368.

BOLINGER, D. (1973). «Essence and Accident: English Analogs of Hispanic Ser / estar», en B. B. KACHRU, Y. MALKIEL y A. PIETRANGELI (eds.), Papers in Honor of Henry and Renée Kahane. Urbana: University of Illinois Press, 58-69.

BULL, W. E. (1942). "New principles for some Spanish equivalent of to be», Hispania, XXV, 433-443.

BULL, W. E. (1965). Spanish for teachers. New York: The Ronald Press Co.

CIROT, G. (1930). «Nouvelles obsevations sur ser et estar», Todd Memorial Volumen, Philological Studies, I, Nueva York: Columbia University Press, 91-122.

CRESPO, L. (1946). «Los verbos ser y estar explicados por un nativo», Hispania, $29,45-55$.

CRESPO, L. (1949). «Ser and Estar: The Solution of the Problem», Hispania, 32, 509-551.

FALK, J. (1979). «Ser y Estar con atributos adjetivales. Anotaciones sobre el empleo de la cópula en catalán y en castellano», I Acta Universitatis Upsaliensis. Studia Romanica Upsaliensia, 29, Uppsala.

FALK, J. (1987). «Reflexiones en torno a Vañó-Cerdá, Ser y Estar + Adjetivos», Studia Neophilologica, 59: 1, 109-128.

FERNÁNDEZ LÓPEZ, J. «Ser y estar - Cómo explicar la diferencia» [en línea] <http:// hispanoteca.eu/Gram\%C3\%A1ticas/Gram\%C3\%A1tica\%20espa\%C3\%B1ola/Ser\%20y\%20Estar\%20-\%20C\%C3\%B3mo\%20explicar\%20la\%20diferencia. htm $>$, fecha de consulta: 17 de enero de 2018.

GILI GAYA, S. (1943). Curso superior de sintaxis española. Barcelona: Ediciones Spes.

HANSSEN, F. (1913). Gramática histórica de la lengua castellana. Halle: Max Niemeyer.

MONGE, F. (1959). «Ser y Estar con participios y adjetivos», Boletim de Filologia. Actas do IX Congresso Internacional de Linguística Românica, Lisboa, 213-222.

MORLEY, S. G. (1925): «Modern Uses of Ser and Estar», PMLA, XI, 450-489.

NAVAS RUIZ, R. (1963). «Ser y estar. Estudio sobre el sistema atributivo del español», Acta Salmanticensia, XVII, 127-139.

NAVAS RUIZ, R. (1977). Ser y estar. El sistema atributivo del español. Salamanca: Ediciones Almar.

NAVAS RUIZ, R. (1984). Ser y estar. La voz pasiva. Salamanca: Publicaciones del Colegio de España. 
OVDINO, C. (1608). Grammatica hispanica, hactenvs galliceexplicata, et aliquoties édita, Avtore Caesare Ovdino, Regio, tom secretario, tum Germanica, Italice E Hispanico linguarum Interprète: Nvnc demvm, vt omnibus Europse nationibus vsui possit esse, recens à viro eiusmodi linguarum studioso, Latinitate donata in lucem prodit. Coloniae: Apud Matthaeum Schmidts. Anno M.DC.VII.

ROLDÁN, M. (1970). «Ser and estar in a New Light», Language Sciences, 12, 17-20.

VAÑÓ-CERDÁ, A. (1982). Ser y estar + Adjetivos. Un estudio sincrónico y diacrónico. Tübingen: Gunter Narr Verlag. 